\title{
Water Intake: Influence on Development of Rat Saline Hypertension
}

Chronic dietary sodium excess leads to the development of arterial hypertension in many species and a given amount of sodium load is usually more effective when added to drinking water than when added to the food of animals drinking water ad lib. SAPIRSTEIN ${ }^{1}$ speculated as early as 1950 that the hypertensinogenic properties of salt loading might be enhanced by associated water restriction, but this hypothesis has really never been tested carefully. We studied this question by selectively controlling and independently varying sodium and water intake in rats.

Materials and methods. Thirty-six male SpragueDawley rats, with a mean body weight of $130 \mathrm{~g}$ and a mean blood pressure of $110 \mathrm{mmHg}$, were randomly divided into 3 equal groups. During the 7 weeks of experiment, all groups ate low salt purina chow $(0.47 \% \mathrm{NaCl})$; their fluid intake was recorded daily, their systolic pressure was measured weekly without anesthesia by tail plethysmography, and they were tube fed with $10 \mathrm{ml}$ of fluid twice a day.

Salt and water regimen and systolic pressure at the end of 7 weeks are summarized in the Figure. Animals in group 1 (Polydipsia) were tube fed with $300 \mathrm{mg}$ of $\mathrm{NaCl} /$ day/rat for 2 weeks, $600 \mathrm{mg}$ for 3 weeks and $900 \mathrm{mg}$ for 2 weeks. They were allowed to drink distilled water containing glucose $3 \%$ and saccharine $0.125 \%{ }^{2}$; their average consumption was $120 \mathrm{ml} / \mathrm{day} / \mathrm{rat}$ at the 7 th week. The final blood pressure in this group, $117 \mathrm{mmHg}$, was not significantly different from the initial value of 114 $\mathrm{mmHg}$. Three deaths were accidental.

Rats in group 2 (ad lib.) were tube fed with the same amount of sodium as group 1 . They drank distilled water ad lib; the average daily consumption was $80 \mathrm{ml}$ at the 7 th week and the final blood pressure was $126 \mathrm{mmHg}$.

Rats in group 3 (thirst) were tube fed with $300 \mathrm{mg}$ of $\mathrm{NaCl}$ per day, dissolved in $20 \mathrm{ml}$ of distilled water, and deprived of any drinking water. 4 rats had died by the end of the 6th week; the others looked weak and had lost weight. Despite their poor shape and the fact that they consumed 3 times less $\mathrm{NaCl}$ than the 2 other groups, their average final blood pressure was the highest at $133 \mathrm{mmHg}$, significantly different from that of the first (Polydipsia) group. Had these rats not been ill, then blood pressure may conceivably have been higher.

Discussion. These data indicate a positive correlation between blood pressure increment and ratio of $\mathrm{NaCl} / \mathrm{H} 20$ consumed rather than with actual amount of ingested salt. This phenomenon, which probably stems from renal inability to concentrate and excrete salt loads without adequate water intake, could explain why salt loading regimens which differ in their degree of water restriction also differ in their hypertensinogenic effectiveness. Thirst could prove to be a useful means for potentiating experimental hypertensions other than saline. Furthermore, surveys trying to link salt consumption of human populations with their blood pressure should include data on water ingestion ${ }^{3}$.

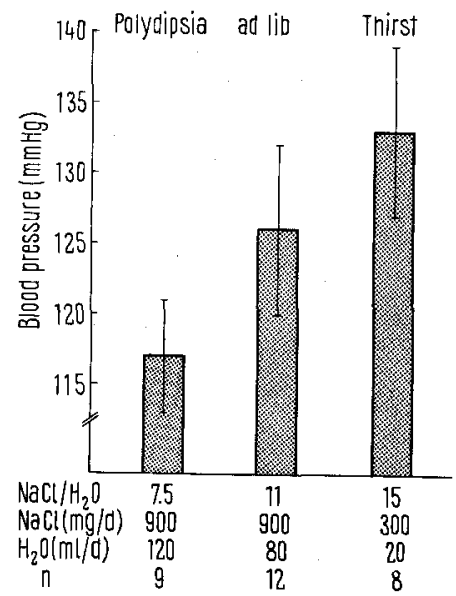

Systolic blood pressure (mean and 95\% confidence interval) of uninephrectomized rats submitted to salt loading for 7 weeks. Values in group (thirst) were significantly higher ( $\beta<0.05$ by variance analysis) than those in group (Polydipsia). Pressure elevation is inversely related to water intake.

Résumé. Après 7 semaines de surcharge saline administrée par gavage, l'augmentation de tension artérielle systolique de 3 groupes de rats uninephrectomisés soumis à différents régimes d'hydratation s'avéra être en meilleure corrélation avec le rapport $\mathrm{NaCl} / \mathrm{H} 20$ ingéré qu'avec la quantité absolue de sodium ingéré. La soif pourrait possiblement potentialiser d'autres formes d'hypertension expérimentale.

Elizabeth Cousineau and P. Biron

Institute of Nutrition and Department of Pharmacology. University of Montreal, Montreal (Canada), 26 July 1971.

1 L. A. Sapirstein, W. L. Brandt and D. H. Druty, Proc. Soc. exp. Biol. Med. 73, 82 (1950).

2 E. S. Valenstein, V. C. Cox and J. W. Kalikewski, Science 157, 552 (1967).

3 Work supported by grants from the Medical Research Council of Canada No. MA-1837 and from the Quebec Heart Foundation.

\section{The Caudate Spindle During Various Sleep Stages}

Little is known of the significance of the striatum (caudate nucleus and putamen) with regard to sleep. R. HESS et al. ${ }^{1}$ have shown that electrical stimulation of the caudate nucleus in the cat causes akinesia. The behaviour of the animals is, however, distinct from that which follows the induction of sleep by thalamic stimulation, being more like a catatonic stupor, although, to quote these authors, the electroencephalographic pattern is difficult to distin- guish from that of spontaneous sleep. HEATH and HodEs ${ }^{2}$ induced drowsiness and sleep in monkeys and humans by electrically stimulating the head of the caudate nucleus, and similar results were obtained by PARMEGGIANI ${ }^{3}$ with cats. HeRnÁNDEZ-PEÓN et al.* initiated sleep in the cat by the local application of acetylcholine to various brain structures, including the caudate nucleus and putamen. It is interesting to note that the latencies of onset of both 